\title{
Coffee Intake in Midlife and Risk of Dementia and its Neuropathologic Correlates
}

\author{
Rebecca P. Gelber ${ }^{a,}{ }^{*}$, Helen Petrovitch ${ }^{b}$, Kamal H. Masaki ${ }^{i}$, G. Webster Ross $^{b}$, and Lon R. \\ White ${ }^{\mathrm{C}}$

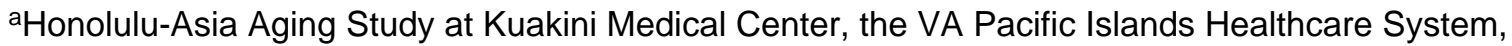 \\ Department of Medicine, University of Hawaii, John A. Burns School of Medicine, Honolulu, HI, \\ USA

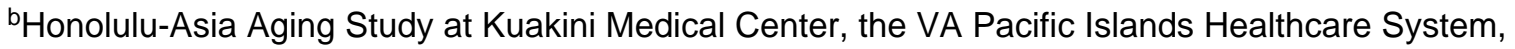 \\ Department of Geriatric Medicine, University of Hawaii, John A. Burns School of Medicine, \\ Honolulu, HI, USA \\ 'Honolulu-Asia Aging Study at Kuakini Medical Center, Department of Geriatric Medicine, \\ University of Hawaii, John A. Burns School of Medicine, Honolulu, HI, USA
}

\begin{abstract}
While animal data suggest a protective effect of caffeine on cognition, studies in humans remain inconsistent. We examined associations of coffee and caffeine intake in midlife with risk of dementia, its neuropathologic correlates, and cognitive impairment among 3494 men in the Honolulu-Asia Aging Study (mean age 52 at cohort entry, 1965-1968) examined for dementia in 1991-1993, including 418 decedents (1992-2004) who underwent brain autopsy. Caffeine intake was determined according to self-reported coffee, tea, and cola consumption at baseline. Logistic regression was used to calculate odds ratios (OR) and 95\% confidence intervals (CI) for overall dementia, Alzheimer's disease (AD), vascular dementia (VaD), cognitive impairment (Cognitive Abilities Screening Instrument score $<74$ ), and neuropathologic lesions at death (Alzheimer lesions, microvascular ischemic lesions, cortical Lewy bodies, hippocampal sclerosis, generalized atrophy), according to coffee and caffeine intake. Dementia was diagnosed in 226 men (including $118 \mathrm{AD}, 80 \mathrm{VaD}$ ), and cognitive impairment in 347. There were no significant associations between coffee or caffeine intake and risk of cognitive impairment, overall dementia, $\mathrm{AD}, \mathrm{VaD}$, or moderate/high levels of the individual neuropathologic lesion types. However, men in the highest quartile of caffeine intake ( $\_411.0 \mathrm{mg} / \mathrm{d}$ ) were less likely than men in the lowest quartile ( $₫ 37.0$ $\mathrm{mg}$ ) to have any of the lesion types (adjusted-OR, $0.45 ; 95 \% \mathrm{CI}, 0.23-0.89$; $p$, trend $=0.04$ ). Coffee and caffeine intake in midlife were not associated with cognitive impairment, dementia, or individual neuropathologic lesions, although higher caffeine intake was associated with a lower odds of having any of the lesion types at autopsy.
\end{abstract}

\section{Keywords}

Caffeine; coffee; cohort studies; dementia

\footnotetext{
(C) 2011 - IOS Press and the authors. All rights reserved

"Correspondence to: Rebecca P. Gelber, MD, DrPH, Kuakini Physicians Tower, 405 N. Kuakini Street, Ste. 1111, Honolulu, HI 96817, USA. Tel.: +1 808547 9706; Fax: +1 808547 9305; rpgelber@ gmail.com..

Authors' disclosures available online (http://www.jalz.com/disclosures/view.php?id=652).
} 


\section{INTRODUCTION}

Recent studies have provided conflicting information on the role of caffeine intake in the development of dementia. Experiments in Alzheimer's disease (AD)-transgenic mice have demonstrated beneficial effects, with improvements in cognition in treated animals [1-3]. Results from epidemiologic studies in humans, however, have been inconclusive, with some suggesting a reduced risk of dementia with higher coffee intake in midlife [4], and others pointing to a lack of association [5].

We therefore examined the associations between midlife coffee and caffeine intake and the risk of dementia, its neuropathologic correlates, and cognitive impairment in late life in a nested case-control study of more than 3400 men ages 71-93 years, for whom standardized information reflecting caffeine intake had been collected at ages $45-65$ years.

\section{METHODS}

\section{Study population}

Data were from the Honolulu-Asia Aging Study (HAAS), a community-based prospective cohort study of 3734 Japanese American men followed since 1965 as part of the Honolulu Heart Program (HHP). Details of the study have been described elsewhere [6, 7]. Briefly, the HHP included 8006 men of Japanese ancestry born between 1900-1919, who were residing on Oahu, Hawaii, in 1964. Information on baseline characteristics, including demographic, dietary, physical activity, and medical history, was obtained through structured interview at the first HHP examination (1965-1968). The HAAS was established in 1991 as an extension of the HHP to study aging-related conditions, with a special focus on brain diseases, and included 3734 men, ages 71-93 years (representing approximately $80 \%$ of surviving members of the original cohort) [7]. The Kuakini Medical Center Institutional Review Board reviewed and approved this study. All participants or their representatives provided written informed consent.

\section{Clinical dementia and cognitive impairment outcomes}

A nested case-control design was used with exposure and covariate information collected prospectively from the HHP cohort in 1965-1968, and cases and controls defined in 19911993, the first time at which dementia case finding and standardized cognitive assessments were performed. Analyses were limited to men with available Cognitive Abilities Screening Instrument (CASI) scores $(n=3734)$ and excluded those with scores $<74$ who did not participate in the dementia evaluation phase $(n=240)$, leaving 3494 men available for analysis.

Case finding was conducted in a multi-step procedure according to a previously described protocol that included screening and standardized dementia evaluations [7]. Briefly, cognitive function of all participants was tested with the 100-point CASI, a combination of the Hasegawa Dementia Screening Scale, the Folstein Mini-Mental State Examination, and the Modified Mini-Mental State Test [8]. Participants with poor CASI scores (<74) and stratified samples from subsets with higher scores were invited to return for the dementia evaluation, accompanied by a proxy informant. Follow-up examinations and the dementia evaluations included a neurologic examination, neuropsychological testing, and informant interview about changes in cognitive function and behavior. Computed tomography or magnetic resonance brain imaging was performed and routine blood tests conducted for men provisionally classified as demented.

Based on these data, a consensus diagnosis for dementia was provided by the study neurologist and two physicians with expertise in dementia, according to criteria of the 
Diagnostic and Statistical Manual of Mental Disorders, third edition, revised (DSM III-R)

[9]. Probable or possible AD was diagnosed according to criteria from the National Institute of Neurological and Communicative Disorders and Stroke-Alzheimer's Disease and Related Disorders Association [10]. Dementia attributed to AD but with minor evidence of coprevalent conditions was classified as possible AD. In a previously examined subset of the HAAS cohort, $77 \%$ of men with the clinical diagnosis of probable pure AD demonstrated sufficient neuritic plaques to meet neuropathological criteria for definite or probable $A D$, while those classified as possible were less often confirmed as definite [11]. Probable or possible vascular dementia $(\mathrm{VaD})$ was diagnosed using criteria of the California Alzheimer's Disease Diagnostic and Treatment Centers [12]. Mixed dementia attributed to $\mathrm{VaD}$ as the primary cause and mixed dementia attributed principally to AD were classified separately. For the purpose of the present analysis, dementia cases classified as AD included probable $\mathrm{AD}$, possible $\mathrm{AD}$, and mixed dementia with major attribution to $\mathrm{AD}$. Dementia cases classified as $\mathrm{VaD}$ included probable $\mathrm{VaD}$, possible $\mathrm{VaD}$, and mixed dementia with dominant attribution to vascular causes.

We defined cognitive impairment as a CASI score $<74$ (16th percentile of scores for all men examined), independent of dementia classification. This corresponds approximately to a score of 22 on the Mini-Mental State Examination, a level often used to indicate cognitive impairment [13]. Substantial overlap existed between cognitive impairment and general (all cause) dementia classifications.

\section{Neuropathologic outcomes}

Of the 3494 men included in the clinical outcome analyses, 418 decedents were autopsied from 1992-2004. These men were included in analyses of midlife coffee and caffeine intake and the presence of neuropathologic lesions at death. Details of the HAAS autopsy protocol and evaluation of the neuropathologic material have been described in detail elsewhere [14, 15]. Permission for the full or limited autopsy was obtained from the next of kin.

We examined each of the following categories of neuropathologic lesions without respect to clinical condition: Alzheimer lesions (neocortical neurofibrillary tangles and neuritic plaques), microvascular ischemic lesions (microinfarcts and lacunar infarcts), neocortical Lewy bodies, hippocampal sclerosis, and generalized brain atrophy. For each of the five lesion categories, decedents were classified using a 3-level lesion index (none/negligible/ low, moderate, and high). As previously described, these indices were developed through a multi-step process to reflect similar strengths of association with cognitive impairment and dementia [14]. For these analyses, each lesion type was defined as being present if moderate or high levels of the lesion were identified.

\section{Assessment of coffee and caffeine intake}

Information on coffee, tea, and cola consumption was obtained from a standardized, validated 24-hour dietary recall administered on all participants at cohort entry (1965-1968) $[16,17]$. Participants reported caffeinated coffee intake as the number of 4-oz cups consumed. For analyses of clinical outcomes, coffee intake categories were defined as 0 , 4$8,12-16,20-24$, and $228 \mathrm{oz} / \mathrm{d}$. For analyses of pathological outcomes, four coffee intake categories were used, given fewer case numbers $(0,4-8,12-16, \geq 20 \mathrm{oz} / \mathrm{d})$. Tea intake was reported as the number of 4-oz cups consumed (without specification of black or green tea), and cola intake as the number of 6-oz cups consumed.

Caffeine intake was calculated based on the estimated caffeine content for coffee $(137 \mathrm{mg} / 8$ $\mathrm{oz}$ ), tea ( $47 \mathrm{mg} / 8 \mathrm{oz}$ ), and cola $(46 \mathrm{mg} / 12 \mathrm{oz}$ ) consumption reported from the 24-hour dietary recall [18]. Caffeine was examined in quintiles for analyses of clinical outcomes and 
in quartiles for analyses of pathological outcomes, given fewer case numbers, with quartiles calculated based on the autopsied subgroup. Caffeine consumption was also assessed as a continuous variable, per standard deviation (SD) unit (223 mg).

\section{Covariates}

Covariates assessed at baseline included age (years, continuous), body mass index (BMI, $<25.0,25.0-29.9, \geq 30.0 \mathrm{~kg} / \mathrm{m}^{2}$ ), physical activity index (tertiles) [19], cigarette smoking (never, past, current), alcohol consumption $(0,>0-<0.5,0.5-<1.0,1.0-<2.0,22.0 \mathrm{drinks} / \mathrm{d})$, education (years of completed schooling), number of childhood years spent in Japan $(<5 /$ 25 ), occupational complexity (a 6-level ordinal scale reflecting average educational attainment), marital status, elevated cholesterol (serum level $\geq 240 \mathrm{mg} / \mathrm{dL}$ ), hypertension (systolic blood pressure [SBP] $2140 \mathrm{mmHg}$, diastolic blood pressure [DBP] $\geq 90 \mathrm{mmHg}$, or history of antihypertensive medication use), diabetes (history of diabetes or use of insulin or oral medications for diabetes), and cardiovascular disease (history of stroke, angina, myocardial infarction, or other coronary heart disease). Genotyping for the presence of apolipoprotein E (APOE) $\varepsilon 4$ ( 1 or 2 alleles vs. none) was performed at Duke University, Durham, NC, using conventional methods [20].

\section{Analysis}

Age-adjusted participant characteristics in midlife were compared according to categories of coffee intake using analysis of variance for continuous variables and logistic regression for categorical variables. Logistic regression was used to calculate odds ratios (ORs) and corresponding 95\% confidence intervals (CIs) for overall dementia, $\mathrm{AD}, \mathrm{VaD}$, their neuropathologic correlates, and cognitive impairment, according to midlife coffee and caffeine intake. The main multivariable-adjusted model included age (age at cohort entry for clinical outcomes and age at death for pathological outcomes), physical activity index, smoking, years of education, hypertension, elevated cholesterol (all assessed at HHP baseline), plus APOE $\varepsilon 4$ status determined at the HAAS examination. A second model further adjusted for baseline BMI, alcohol consumption, number of childhood years spent in Japan, history of diabetes mellitus, cardiovascular disease, occupational complexity, and marital status, in addition to the variables included in the main model.

Separate models included joint terms to evaluate potential interactions between coffee intake and smoking status (never, past, current), physical activity index (tertile 3 vs. 1/2), and BMI $\left(</ \geq 25.0 \mathrm{~kg} / \mathrm{m}^{2}\right)$. The likelihood ratio test (LRT) was used to assess for statistically significant effect modification, contrasting age-adjusted models with and without interaction terms of interest. Tests for linear trends in the OR across categories of exposure were performed using the LRT, assigning median values to each category where appropriate.

In secondary analyses, linear regression was used to examine associations between coffee and caffeine intake and CASI score as a continuous variable. Mean caffeine intake was compared between groups of decedents defined by the presence of neuropathologic lesions using general linear models. Two-sided $p$-values were reported in all analyses. $p$-values $<0.05$ were considered statistically significant. All data analyses were performed using SAS Software Version 9.2 (SAS Institute Inc, Cary, NC).

\section{RESULTS}

Participant characteristics are shown according to midlife coffee intake in Table 1. Men who consumed more coffee were slightly younger, less likely to have hypertension, more likely to have high cholesterol and to smoke, and tended to be less physically active. 
A total of 226 cases of dementia (including $118 \mathrm{AD}, 80 \mathrm{VaD}$ ) and 347 cases of cognitive impairment were diagnosed 25 years following cohort entry. Coffee (Table 2) and caffeine (Table 3) intake were not significantly associated with overall dementia, AD, VaD, or cognitive impairment adjusting for age, with similar results after adjustment for the main potential confounders. Further adjustment for BMI, alcohol consumption, diabetes, cardiovascular disease, occupational complexity, marital status, and childhood years spent in Japan did not materially alter the results. Coffee and caffeine consumption were also not associated with CASI score as a continuous variable (data not shown).

Coffee intake was not significantly associated with overall dementia in analyses stratified by smoking status using joint terms (LRT, $p=0.66$ ), nor was there evidence for effect modification by midlife physical activity or BMI (LRT, $p=0.69$ and 0.78 , respectively). Similarly, there were no significant associations with cognitive impairment examining the joint effects of coffee intake and smoking status, physical activity, or BMI (data not shown).

Among 418 decedents, there were no significant associations between midlife coffee (Table 4) or caffeine (Table 5) intake and the presence of Alzheimer lesion, microvascular ischemic lesions, generalized atrophy, cortical Lewy bodies, or hippocampal sclerosis at autopsy. However, the risk of having any of the lesions was decreased among those in the highest quartile of caffeine intake (multivariable-adjusted OR, 0.45; 95\% CI, 0.23-0.89; LRT $p$, trend $=0.04$; Table 5). Examining caffeine as a continuous variable, per SD-unit (223 mg), there were no significant associations with any of the clinical outcomes or with specific neuropathologic lesions at death. However, caffeine intake was again associated with the presence of any of the lesions. Adjusting for age at death, the OR for having any lesions, as compared to no lesions, was 0.78 (95\% CI, 0.64-0.96). Additionally adjusting for education, APOE $\varepsilon 4$ status, smoking, physical activity, elevated cholesterol, and history of hypertension, the OR for any lesions was 0.77 (95\% CI, 0.61-0.97).

Mean caffeine intake in midlife was $276 \mathrm{mg}$ among the 154 decedents with microvascular ischemic lesions, as compared to $333 \mathrm{mg}$ among the 121 decedents without any lesions, adjusting for age at death, years of education, and APOE $\varepsilon 4$ status $(p=0.06)$. Adjusted mean caffeine intake among decedents with $\mathrm{AD}$ lesions was $279 \mathrm{mg}$ ( $p=0.10$, as compared to those without any lesions).

\section{DISCUSSION}

In this nested case-control study, coffee and caffeine intake in midlife were not associated with overall dementia, AD, $\mathrm{VaD}$, or cognitive impairment after 25 years. Among decedents, the highest level of caffeine consumption was associated with a lower risk of having any of the neuropathologic lesions, however, there were no significant associations according to lesion type.

The association between the highest level of caffeine intake and a lower OR for having moderate/high levels of any of the lesion types may reflect a causal relationship. Analyses of some of the specific lesion types may not have reached statistical significance due to limited case numbers, and it is plausible that caffeine serves a protective role common to the development of co-prevalent lesion types. Caffeine, an adenosine receptor antagonist, acts as a brain stimulant acutely and enhances alertness [21]. Recent studies in mice have supported a protective role of caffeine exposure in the development of cognitive impairment, the restoration of cognition, and the reversal of $\mathrm{AD}$ pathology, suggesting a potentially therapeutic and preventive role of caffeine in $\mathrm{AD}$ [1-3]. Furthermore, higher caffeine intake has been associated with fewer white matter lesions on magnetic resonance brain imaging in 
women [22]. Caffeine has also been shown in multiple studies to have a protective role in the development of Parkinson's disease [23, 24].

However, previous epidemiologic studies of caffeine intake and cognition in humans have provided inconsistent results [25]. In a case-control study from Portugal, caffeine intake was associated with a lower risk of AD [26]. However, caffeine consumption was assessed retrospectively as the average intake over the prior 20 years. A subsequent study from Finland suggested that midlife coffee intake decreased risk of late life AD and any dementia [4], whereas another study among Finnish twins did not show any associations [5]. In prospective cohort studies from France [27] and Portugal [28] among men and women $\succ 65$ years of age, higher coffee intake was associated with reduced cognitive decline among women over the ensuing 4 years, however, midlife coffee intake and long-term effects were not examined.

Our study has several strengths, including the standardized, prospective collection of information on risk factors and multiple potential confounders, the community-based and longitudinal study design, a large number of participants with high response rates at the baseline and follow-up examinations, and highly standardized clinical and neuropathologic endpoints. Furthermore, previous analyses have provided robust demonstrations of the relationship of midlife coffee and caffeine intake with another neurologic condition, Parkinson's disease [23].

Several limitations should be considered in the interpretation of our results. The cohort included only Japanese American men residing on Oahu, which thereby limits generalizability of our results. However, limiting the study demographic also reduces potential confounding due to ethnicity and geography. Secondly, calculation of caffeine intake was likely imprecise, based on 24-hour recall of coffee, tea, and cola intake, without information on caffeine from food, such as chocolate. However, we expect that any misclassification of caffeine intake would have been random with respect to outcome assessment. Lastly, we did not analyze incident cases of dementia following exposure assessment, but rather identified prevalent cases after 25 years. However, censoring and death prior to case ascertainment may be expected to lead to underestimates of associations between caffeine intake and risk of dementia. Furthermore, although dementia may have initially developed years earlier, it is unlikely that participants were demented at the time of risk factor assessment in midlife.

In conclusion, our study does not support an association between midlife coffee or caffeine intake and the risk of dementia or cognitive impairment. The highest levels of caffeine consumption was associated with a decreased risk of having any of the neuropathologic correlates of dementia at autopsy, however, there were no associations with specific lesion types. Further prospective studies and future clinical trials of caffeine intake, while challenging [29], are needed to confirm our findings.

\section{Acknowledgments}

This work was supported by grants 5U01 AG017155-09, 3U01 AG017155-09S1, and 5U01 AG19349-09 from the National Institutes of Health and Aging and resources from the VA Pacific Islands Health Care System. The information in this paper does not necessarily reflect the position or the policy of the government and no official endorsement should be inferred.

We are indebted to the participants in the Honolulu-Asia Aging Study for their outstanding commitment and to the entire staff of the Honolulu-Asia Aging Study for their expert assistance. 


\section{REFERENCES}

1. Cao C, Cirrito JR, Lin X, Wang L, Verges DK, Dickson A, Mamcarz M, Zhang C, Mori T, Arendash GW, Holtzman DM, Potter H. Caffeine suppresses amyloid-beta levels in plasma and brain of Alzheimer's disease transgenic mice. J Alzheimers Dis. 2009; 17:681-697. [PubMed: 19581723]

2. Arendash GW, Mori T, Cao C, Mamcarz M, Runfeldt M, Dickson A, Rezai-Zadeh K, Tane J, Citron BA, Lin X, Echeverria V, Potter H. Caffeine reverses cognitive impairment and decreases brain amyloid-beta levels in aged Alzheimer's disease mice. J Alzheimers Dis. 2009; 17:661-680. [PubMed: 19581722]

3. Arendash GW, Schleif W, Rezai-Zadeh K, Jackson EK, Zacharia LC, Cracchiolo JR, Shippy D, Tan J. Caffeine protects Alzheimer's mice against cognitive impairment and reduces brain beta-amyloid production. Neuroscience. 2006; 142:941-952. [PubMed: 16938404]

4. Eskelinen MH, Ngandu T, Tuomilehto J, Soininen H, Kivipelto M. Midlife coffee and tea drinking and the risk of late-life dementia: a population-based CAIDE study. J Alzheimers Dis. 2009; 16:8591. [PubMed: 19158424]

5. Laitala VS, Kaprio J, Koskenvuo M, Raiha I, Rinne JO, Silventoinen K. Coffee drinking in middle age is not associated with cognitive performance in old age. Am J Clin Nutr. 2009; 90:640-646. [PubMed: 19587088]

6. Syme SL, Marmot MG, Kagan A, Kato H, Rhoads G. Epidemiologic studies of coronary heart disease and stroke in Japanese men living in Japan, Hawaii and California: introduction. Am J Epidemiol. 1975; 102:477-480. [PubMed: 1202949]

7. White L, Petrovitch H, Ross GW, Masaki KH, Abbott RD, Teng EL, Rodriguez BL, Blanchette PL, Havlik RJ, Wergowske G, Chiu D, Foley DJ, Murdaugh C, Curb JD. Prevalence of dementia in older Japanese-American men in Hawaii: The Honolulu-Asia Aging Study. JAMA. 1996; 276:955960. [PubMed: 8805729]

8. Teng EL, Hasegawa K, Homma A, Imai Y, Larson E, Graves A, Sugimoto K, Yamaguchi T, Sasaki H, Chiu D, et al. The Cognitive Abilities Screening Instrument (CASI): a practical test for crosscultural epidemiological studies of dementia. Int Psychogeriatr. 1994; 6:45-58. discussion 62. [PubMed: 8054493]

9. American Psychiatric Association. Diagnostic and Statistical Manual of Mental Disorders. third edition, revised. American Psychiatric Association; Washington, DC.: 1987.

10. McKhann G, Drachman D, Folstein M, Katzman R, Price D, Stadlan EM. Clinical diagnosis of Alzheimer's disease: report of the NINCDS-ADRDA Work Group under the auspices of Department of Health and Human Services Task Force on Alzheimer's Disease. Neurology. 1984; 34:939-944. [PubMed: 6610841]

11. Petrovitch H, White LR, Ross GW, Steinhorn SC, Li CY, Masaki KH, Davis DG, Nelson J, Hardman J, Curb JD, Blanchette PL, Launer LJ, Yano K, Markesbery WR. Accuracy of clinical criteria for AD in the Honolulu-Asia Aging Study, a population-based study. Neurology. 2001; 57:226-234. [PubMed: 11468306]

12. Chui HC, Victoroff JI, Margolin D, Jagust W, Shankle R, Katzman R. Criteria for the diagnosis of ischemic vascular dementia proposed by the State of California Alzheimer's Disease Diagnostic and Treatment Centers. Neurology. 1992; 42:473-480. [PubMed: 1549205]

13. Abbott RD, White LR, Ross GW, Masaki KH, Curb JD, Petrovitch H. Walking and dementia in physically capable elderly men. JAMA. 2004; 292:1447-1453. [PubMed: 15383515]

14. White L. Brain lesions at autopsy in older Japanese-American men as related to cognitive impairment and dementia in the final years of life: a summary report from the Honolulu-Asia aging study. J Alzheimers Dis. 2009; 18:713-725. [PubMed: 19661625]

15. Petrovitch H, Ross GW, Steinhorn SC, Abbott RD, Markesbery W, Davis D, Nelson J, Hardman J, Masaki K, Vogt MR, Launer L, White LR. AD lesions and infarcts in demented and non-demented Japanese-American men. Ann Neurol. 2005; 57:98-103. [PubMed: 15562458]

16. Hankin JH, Nomura A, Rhoads GG. Dietary patterns among men of Japanese ancestry in Hawaii. Cancer Res. 1975; 35:3259-3264. [PubMed: 1192401] 
17. McGee D, Rhoads G, Hankin J, Yano K, Tillotson J. Within-person variability of nutrient intake in a group of Hawaiian men of Japanese ancestry. Am J Clin Nutr. 1982; 36:657-663. [PubMed: 7124667]

18. Lopez-Garcia E, Rodriguez-Artalejo F, Rexrode KM, Logroscino G, Hu FB, van Dam RM. Coffee consumption and risk of stroke in women. Circulation. 2009; 119:1116-1123. [PubMed: 19221216]

19. Taaffe DR, Irie F, Masaki KH, Abbott RD, Petrovitch H, Ross GW, White LR. Physical activity, physical function, and incident dementia in elderly men: the Honolulu-Asia Aging Study. $\mathbf{J}$ Gerontol A Biol Sci Med Sci. 2008; 63:529-535. [PubMed: 18511759]

20. Hixson JE, Vernier DT. Restriction isotyping of human apolipoprotein E by gene amplification and cleavage with HhaI. J Lipid Res. 1990; 31:545-548. [PubMed: 2341813]

21. Fredholm BB, Battig K, Holmen J, Nehlig A, Zvartau EE. Actions of caffeine in the brain with special reference to factors that contribute to its widespread use. Pharmacol Rev. 1999; 51:83-133. [PubMed: 10049999]

22. Ritchie K, Artero S, Portet F, Brickman A, Muraskin J, Beanino E, Ancelin ML, Carriere I. Caffeine, cognitive functioning, and white matter lesions in the elderly: establishing causality from epidemiological evidence. J Alzheimers Dis. 2010; 20(Suppl 1):S161-S166. [PubMed: 20164564]

23. Ross GW, Abbott RD, Petrovitch H, Morens DM, Grandinetti A, Tung KH, Tanner CM, Masaki KH, Blanchette PL, Curb JD, Popper JS, White LR. Association of coffee and caffeine intake with the risk of Parkinson disease. JAMA. 2000; 283:2674-2679. [PubMed: 10819950]

24. Prediger RD. Effects of caffeine in Parkinson's disease: from neuroprotection to the management of motor and non-motor symptoms. J Alzheimers Dis. 2010; 20(Suppl 1):S205-S220. [PubMed: 20182024]

25. Santos C, Costa J, Santos J, Vaz-Carneiro A, Lunet N. Caffeine intake and dementia: systematic review and meta-analysis. J Alzheimers Dis. 2010; 20(Suppl 1):S187-S204. [PubMed: 20182026]

26. Maia L, de Mendonca A. Does caffeine intake protect from Alzheimer's disease? Eur J Neurol. 2002; 9:377-382. [PubMed: 12099922]

27. Ritchie K, Carriere I, de Mendonca A, Portet F, Dartigues JF, Rouaud O, Barberger-Gateau P, Ancelin ML. The neuroprotective effects of caffeine: a prospective population study (the Three City Study). Neurology. 2007; 69:536-545. [PubMed: 17679672]

28. Santos C, Lunet N, Azevedo A, de Mendonca A, Ritchie K, Barros H. Caffeine intake is associated with a lower risk of cognitive decline: a cohort study from Portugal. J Alzheimers Dtis. 2010; 20(Suppl 1):S175-S185.

29. de Mendonca A, Cunha RA. Putative neuroprotective effects of caffeine in clinical trials. Concluding remarks. J Alzheimers Dis. 2010; 20(Suppl 1):S249-S252. [PubMed: 20448306] 


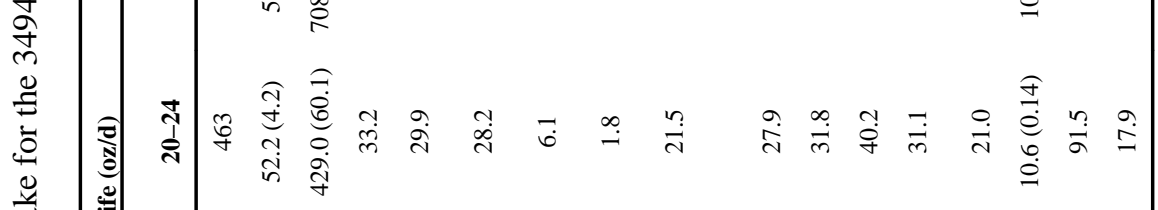

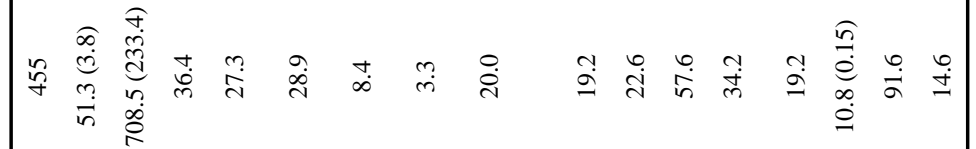

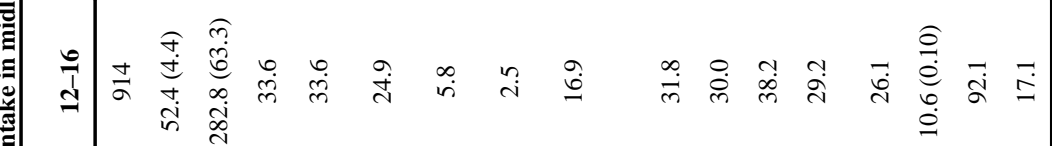

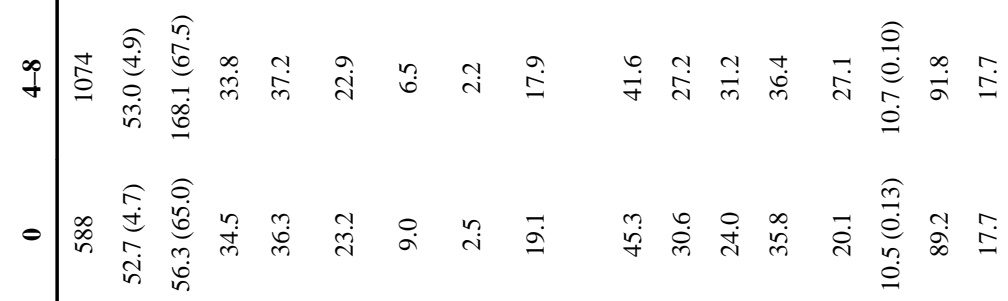




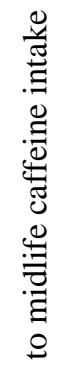

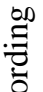

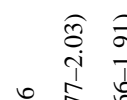

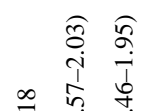

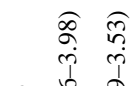

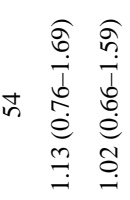

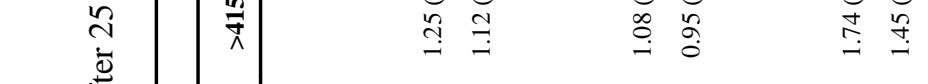

$-\hat{e}$

$\stackrel{\infty}{\frac{0}{0}}$

营

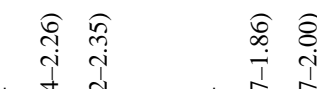

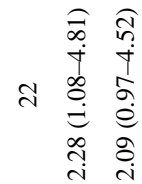

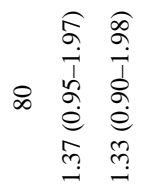

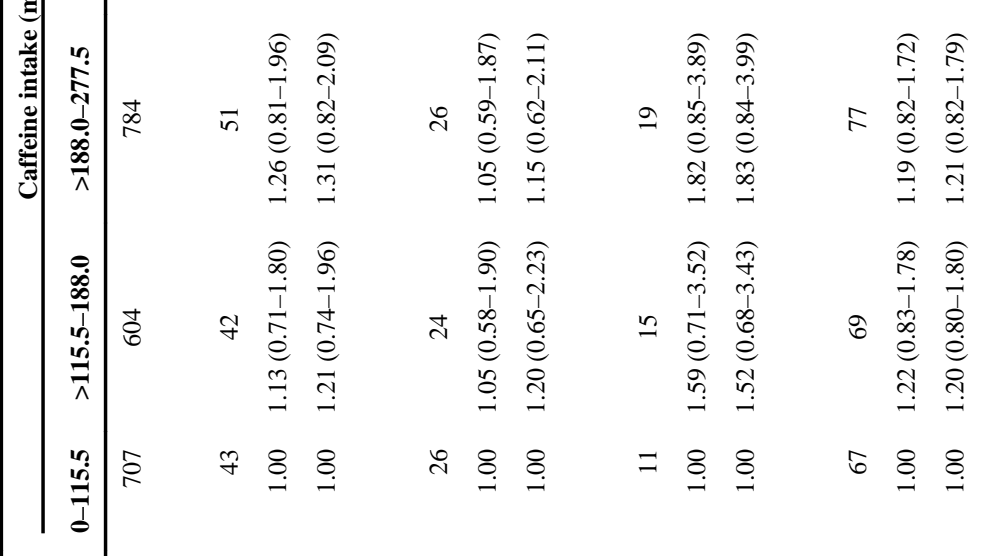

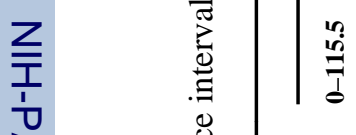

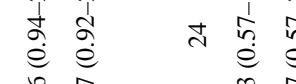

$\begin{array}{ll}n & 1 \\ 2 & n \\ e & 0 \\ 0 & 5\end{array}$

$\frac{3}{0}$ 
Table 4

Odds ratios (95\% confidence intervals) for brain pathology according to midlife coffee intake among 418 decedents, 1992-2004

\begin{tabular}{|c|c|c|c|c|}
\hline & \multicolumn{4}{|c|}{ Coffee intake in midlife (oz/d) } \\
\hline & $\mathbf{0}$ & 4-8 & $12-16$ & $\geq 20$ \\
\hline No. of men & 64 & 137 & 103 & 114 \\
\hline \multicolumn{5}{|l|}{ Alzheimer lesions } \\
\hline No. of cases & 14 & 31 & 30 & 28 \\
\hline Age-adjusted & 1.00 & $1.02(0.49-2.11)$ & $1.56(0.74-3.29)$ & $1.20(0.57-2.52)$ \\
\hline Multivariable-adjusted ${ }^{*}$ & 1.00 & $1.16(0.53-2.54)$ & $1.82(0.81-4.08)$ & $1.02(0.44-2.37)$ \\
\hline \multicolumn{5}{|l|}{ Microvascular ischemic lesions } \\
\hline No. of cases & 28 & 53 & 39 & 34 \\
\hline Age-adjusted & 1.00 & $0.81(0.44-1.48)$ & $0.79(0.42-1.49)$ & $0.55(0.29-1.04)$ \\
\hline Multivariable-adjusted ${ }^{*}$ & 1.00 & $0.80(0.42-1.49)$ & $0.84(0.43-1.62)$ & $0.58(0.29-1.15)$ \\
\hline \multicolumn{5}{|l|}{ Generalized atrophy } \\
\hline No. of cases & 28 & 63 & 47 & 50 \\
\hline Age-adjusted & 1.00 & $1.06(0.57-1.96)$ & $1.12(0.59-2.13)$ & $1.02(0.54-1.92)$ \\
\hline Multivariable-adjusted ${ }^{*}$ & 1.00 & $1.20(0.63-2.27)$ & $1.30(0.66-2.55)$ & $1.24(0.62-2.48)$ \\
\hline \multicolumn{5}{|l|}{ Cortical Lewy bodies } \\
\hline No. of cases & 14 & 20 & 16 & 13 \\
\hline Age-adjusted & 1.00 & $0.59(0.27-1.27)$ & $0.67(0.30-1.50)$ & $0.46(0.20-1.07)$ \\
\hline Multivariable-adjusted ${ }^{*}$ & 1.00 & $0.63(0.28-1.40)$ & $0.76(0.33-1.76)$ & $0.52(0.21-1.31)$ \\
\hline \multicolumn{5}{|l|}{ Hippocampal sclerosis } \\
\hline No. of cases & 9 & 12 & 8 & 9 \\
\hline Age-adjusted & 1.00 & $0.56(0.22-1.44)$ & $0.53(0.19-1.48)$ & $0.54(0.20-1.45)$ \\
\hline Multivariable-adjusted ${ }^{*}$ & 1.00 & $0.50(0.18-1.40)$ & $0.65(0.22-1.93)$ & $0.64(0.21-1.97)$ \\
\hline \multicolumn{5}{|l|}{ Any lesions } \\
\hline No. of cases & 49 & 100 & 75 & 72 \\
\hline Age-adjusted & 1.00 & $0.78(0.39-1.59)$ & $0.83(0.40-1.72)$ & $0.51(0.25-1.03)$ \\
\hline Multivariable-adjusted ${ }^{*}$ & 1.00 & $0.84(0.40-1.74)$ & $1.00(0.46-2.17)$ & $0.52(0.24-1.13)$ \\
\hline
\end{tabular}

* Adjusts for age at death, physical activity index, smoking, years of education, APOE $\varepsilon 4$ status, elevated cholesterol, and hypertension. 
Table 5

Odds ratios (95\% confidence intervals) for brain pathology according to midlife caffeine intake among 418 decedents, 1992-2004

\begin{tabular}{|c|c|c|c|c|}
\hline & \multicolumn{4}{|c|}{ Caffeine intake, quartiles (mg/d) } \\
\hline & $0-137.0$ & 138.5-231.0 & 251.5-391.5 & $411.0-1872.5$ \\
\hline No. of men & 109 & 99 & 105 & 105 \\
\hline \multicolumn{5}{|l|}{ Alzheimer lesions } \\
\hline No. of cases & 27 & 25 & 25 & 26 \\
\hline Age-adjusted & 1.00 & $1.00(0.53-1.90)$ & $0.98(0.52-1.84)$ & $1.03(0.55-1.93)$ \\
\hline Multivariable-adjusted $^{*}$ & 1.00 & $1.10(0.55-2.18)$ & $0.96(0.48-1.90)$ & $0.85(0.42-1.73)$ \\
\hline \multicolumn{5}{|c|}{ Microvascular ischemic lesions } \\
\hline No. of cases & 43 & 46 & 31 & 34 \\
\hline Age-adjusted & 1.00 & $1.31(0.75-2.27)$ & $0.64(0.36-1.12)$ & $0.73(0.42-1.28)$ \\
\hline Multivariable-adjusted ${ }^{*}$ & 1.00 & $1.27(0.72-2.26)$ & $0.66(0.37-1.20)$ & $0.79(0.43-1.45)$ \\
\hline \multicolumn{5}{|l|}{ Generalized atrophy } \\
\hline No. of cases & 54 & 40 & 46 & 48 \\
\hline Age-adjusted & 1.00 & $0.66(0.37-1.16)$ & $0.80(0.46-1.40)$ & $0.87(0.50-1.52)$ \\
\hline Multivariable-adjusted ${ }^{*}$ & 1.00 & $0.68(0.38-1.22)$ & $0.87(0.49-1.55)$ & $1.01(0.56-1.84)$ \\
\hline \multicolumn{5}{|l|}{ Cortical Lewy bodies } \\
\hline No. of cases & 19 & 14 & 18 & 12 \\
\hline Age-adjusted & 1.00 & $0.76(0.36-1.62)$ & $0.99(0.49-2.03)$ & $0.62(0.28-1.36)$ \\
\hline Multivariable-adjusted $^{*}$ & 1.00 & $0.82(0.38-1.80)$ & $1.10(0.52-2.31)$ & $0.71(0.30-1.66)$ \\
\hline \multicolumn{5}{|l|}{ Hippocampal sclerosis } \\
\hline No. of cases & 13 & 9 & 8 & 8 \\
\hline Age-adjusted & 1.00 & $0.71(0.29-1.77)$ & $0.61(0.24-1.56)$ & $0.63(0.25-1.60)$ \\
\hline Multivariable-adjusted ${ }^{*}$ & 1.00 & $0.67(0.25-1.78)$ & $0.62(0.23-1.71)$ & $0.77(0.27-2.20)$ \\
\hline \multicolumn{5}{|l|}{ Any lesions } \\
\hline No. of cases & 87 & 70 & 71 & 68 \\
\hline Age-adjusted & 1.00 & $0.59(0.31-1.12)$ & $0.53(0.28-1.00)$ & $0.46(0.25-0.86)$ \\
\hline Multivariable-adjusted $^{*}$ & 1.00 & $0.61(0.31-1.20)$ & $0.57(0.30-1.10)$ & $0.45(0.23-0.89)$ \\
\hline
\end{tabular}

